\title{
Effects of salt stress on ion balance and nitrogen metabolism of old and young leaves in rice (Oryza sativa L.)
}

Huan Wang ${ }^{1}$, Meishan Zhang ${ }^{2}$, Rui Guo ${ }^{3}$, Decheng Shi', Bao Liu', Xiuyun Lin ${ }^{4}$ and Chunwu Yang ${ }^{1 *}$

\begin{abstract}
Background: It is well known that salt stress has different effects on old and young tissues. However, it remains largely unexplored whether old and young tissues have different regulatory mechanism during adaptation of plants to salt stress. The aim of this study was to investigate whether salt stress has different effects on the ion balance and nitrogen metabolism in the old and young leaves of rice, and to compare functions of both organs in rice salt tolerance.

Results: Rice protected young leaves from ion harm via the large accumulation of $\mathrm{Na}^{+}$and $\mathrm{Cl}^{-}$in old leaves. The up-regulation of OsHKT1;1, OsHAK10 and OsHAK16 might contribute to accumulation of $\mathrm{Na}^{+}$in old leaves under salt stress. In addition, lower expression of OsHKT1;5 and OsSOS1 in old leaves may decrease frequency of retrieving $\mathrm{Na}^{+}$ from old leaf cells. Under salt stress, old leaves showed higher concentration of $\mathrm{NO}_{3}^{-}$content than young leaves. Up-regulation of OsNRT1;2, a gene coding nitrate transporter, might contribute to the accumulation of $\mathrm{NO}_{3}^{-}$in the old leaves of salt stressed-rice. Salt stress clearly up-regulated the expression of OsGDH2 and OsGDH3 in old leaves, while strongly down-regulated expression of OsGS2 and OsFd-GOGAT in old leaves.
\end{abstract}

Conclusions: The down-regulation of OsGS2 and OsFd-GOGAT in old leaves might be a harmful response to excesses of $\mathrm{Na}^{+}$and $\mathrm{Cl}^{-}$. Under salt stress, rice might accumulate $\mathrm{Na}^{+}$and $\mathrm{Cl}^{-}$to toxic levels in old leaves. This might influence photorespiration process, reduce $\mathrm{NH}_{4}^{+}$production from photorespiration, and immediately down-regulate the expression of OsGS2 and OsFd-GOGAT in old leaves of salt stressed rice. Excesses of $\mathrm{Na}^{+}$and $\mathrm{Cl}^{-}$also might change the pathway of $\mathrm{NH}_{4}^{+}$assimilation in old leaves of salt stressed rice plants, weaken GOGAT/GS pathway and elevate GDH pathway.

Keywords: Salt stress, Rice, Nitrogen metabolism, Gene expression, Old and young leaves

\section{Background}

Salinity is one of most prevalent abiotic stresses that limit crop productivity in arid and semi-arid regions. Salt tolerance of plants is a complex phenomenon that involves morphological and developmental changes as well as physiological and biochemical processes [1,2]. Response by plants to salt stress is a complex network affecting almost all processes, including nutrient uptake and metabolism, ion accumulation and photosynthesis. Salt stress in the soil generally involves osmotic stress and ion injury [3]. High salt environments can break the

\footnotetext{
* Correspondence: chunwuyang@gmail.com

${ }^{1}$ Key laboratory of Molecular Epigenetics of MOE, Northeast Normal

University, Changchun 130024 Jilin Province, China

Full list of author information is available at the end of the article
}

ion homeostasis of plant cells, destroy the ionic balance, and affect the distributions of $\mathrm{K}^{+}$and $\mathrm{Na}^{+}$in the cells [4]. It is necessary to re-establish the ion homeostasis in cells for plant living under salt-stress [4]. Plant survival and growth in saline environments is a result of adaptive processes such as ion transport and compartmentation, compatible solutes synthesis and accumulation. Many of these compatible solutes are $\mathrm{N}$-containing compounds, such as amino acids and betaines, hence the nitrogen metabolism is of central importance for salt tolerance [5].

It is well known that salt stress has different effects on old and young tissues [6]. For example, salt stress produces distinct effects on the growth and $\mathrm{Na}^{+}$accumulation of old and young leaves [7-11]. It is widely believed

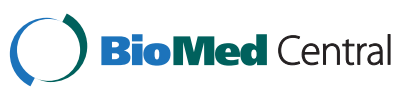


that old and young tissues play distinct roles in salt tolerance and plants protect young leaves from ion harm via the large accumulation of toxic ions like $\mathrm{Na}^{+}$in old leaves during adaptation to salt stress [3,7-12]. Thus, the understanding of comparative effects of salt stress on old and young tissues may be important for salt tolerance research. Although plant biologists have extensively reported the difference between old and young tissues, many questions remain. For example, how do old and young tissues regulate ion balance in response of plants to salt stress? whether salt stress has different effects on nitrogen metabolism of old and young leaves?

Salt stress in soil generally involves osmotic stress and ion-induced injury, and $\mathrm{Na}^{+}$is the main toxic ion in salinized soil. Low $\mathrm{Na}^{+}$and high $\mathrm{K}^{+}$in the cytoplasm are essential for the maintenance of a number of enzymatic processes. Transmembrane $\mathrm{K}^{+}$movements in plants are mediated by several types of channels, including the AKT family, and by transporters that belong to two families, KcsA-TRK (HKT) and KUP/HAK/KT (HAK). The extent of tolerance by plants to $\mathrm{Na}^{+}$stress depends on ion compartmentalization and exclusion. In higher plants, the salt overly sensitive protein 1 (SOS1) functions in $\mathrm{Na}^{+}$exclusion from root epidermal cells into the rhizosphere, which also plays a role in retrieving $\mathrm{Na}^{+}$ from shoots to roots [3]. SOS3-SOS2 (CIPK24-CBL4) protein kinase pathway mediates regulation of the expression and activities of $\mathrm{Na}^{+}$transporters such as SOS1 and $\mathrm{Na}^{+} / \mathrm{H}^{+}$exchanger (NHX) that mediates $\mathrm{Na}^{+}$ compartmentalization into vacuoles [3]. In rice plants, a high affinity $\mathrm{K}^{+}$transporter (HKT) family, OsHKT1;5, mediates $\mathrm{Na}^{+}$exclusion from shoots via $\mathrm{Na}^{+}$removal from the xylem sap [3].

Plant roots absorb nitrate $\left(\mathrm{NO}_{3}^{-}\right)$, ammonium $\left(\mathrm{NH}_{4}^{+}\right)$, and other nutrients from soil using a variety of transporters. For example, AMT protein family members transport $\mathrm{NH}_{4}^{+}$and NRT protein family members transport nitrate. $\mathrm{NO}_{3}^{-}$is reduced to nitrite by nitrate reductase (NR) and then to $\mathrm{NH}_{4}^{+}$by nitrite reductase $(\mathrm{NiR}) . \mathrm{NH}_{4}^{+}$from both nitrate reduction and soil are incorporated into amino acid by glutamine synthetase (GS) and glutamate synthase (Fd-GOGAT and NADHGOGAT) or alternative glutamate dehydrogenase (GDH) pathway [13].

The study was designed to investigate whether salt stress has different effects on the ion balance and nitrogen metabolism in the old and young leaves of rice, and to compare functions of both organs in rice salt tolerance. The rice seedlings were subjected to salt stress. The contents of inorganic ions, $\mathrm{NH}_{4}^{+}$-nitrogen, and $\mathrm{NO}_{3}^{-}$-nitrogen in old and young leaves were then measured. The expression of some critical genes involved in ion balance and nitrogen metabolism also were assayed to test their roles in salt tolerance.

\section{Results}

\section{Ion accumulation}

Salt stress only slightly influenced accumulations of $\mathrm{Na}^{+}$, $\mathrm{K}^{+}, \mathrm{Na}^{+} / \mathrm{K}^{+}$ratio, $\mathrm{Cl}^{-}$and ammoniacal nitrogen in young leaves, but strongly stimulated their accumulation in old leaves (Figure 1). Salt stress reduced $\mathrm{NO}_{3}^{-}$contents in both old and young leaves, with reduction in young leaves greater than in old leaves. Although the $\mathrm{NO}_{3}^{-}$content was much higher in old leaves than young leaves under salt stress (Figure 1E), substantial differences between both organs are not found in their $\mathrm{SO}_{4}^{2-}$ and $\mathrm{H}_{2} \mathrm{PO}_{4}^{-}$contents (Figure 1).

\section{Ion metabolism}

Salt stress slightly down-regulated the expression levels of OsCBL4, OsHKT1;1 and OsNHX1 in young leaves, while strongly stimulated their expression in old leaves (Figure 2). Salt stress stimulated the expression of OsHKT1;5 in young leaves but down-regulated its expression in old leaves (Figure 2F). The expression of OsHKT1;3 and OsHKT2;1 in young leaves were lower than old leaves (Figure 2). Expression levels of OsHAK10 and OsHAK16 in young leaves were down-regulated by salt stress, whereas their expression levels in old leaves were enhanced (Figure 3). Salt stress mightily upregulated expression of OsHAK4 in young leaves but reduced its expression in old leaves (Figure $3 \mathrm{C}$ ). The expression level of OsAKT1 in old leaves clearly decreased, while in young leaves increased (Figure 3A).

\section{$\mathrm{NH}_{4}^{+}$assimilation}

Effects of salt stress on the expression of OsNR1, OsGS1;1, OsGS1;2, OsGS1;3, OsGDH2 and OsGDH3 in young leaves were insignificant, while their expression in old leaves were strongly up-regulated (Figure 4). Salt stress lowered the expression of $O s N i R$ in old leaves, and enhanced its expression in young leaves. The expression levels of OsNADH-GOGAT2, OsAS, OsGS2 and OsFd-GOGAT in both organs were down-regulated by salt stress (Figure 4), while expression levels of the four genes all were much lower in old leaves than in young leaves. Under control condition, expression level of OsGS2 was much higher than other OsGS family members (Figure 5). Under salt stress, percent contribution of OsGS2 to total OsGS expression in young leaves still was much higher than other members; however, in old leaves, expression of all OsGS1 gene family members were clearly up-regulated and resulted in the reduction of percent contribution of OsGS2 (Figure 5).

\section{Nitrogen uptake}

Salt stress strongly stimulated the expression of OsNRT1;2 in old leaves, but down-regulated the expression of 


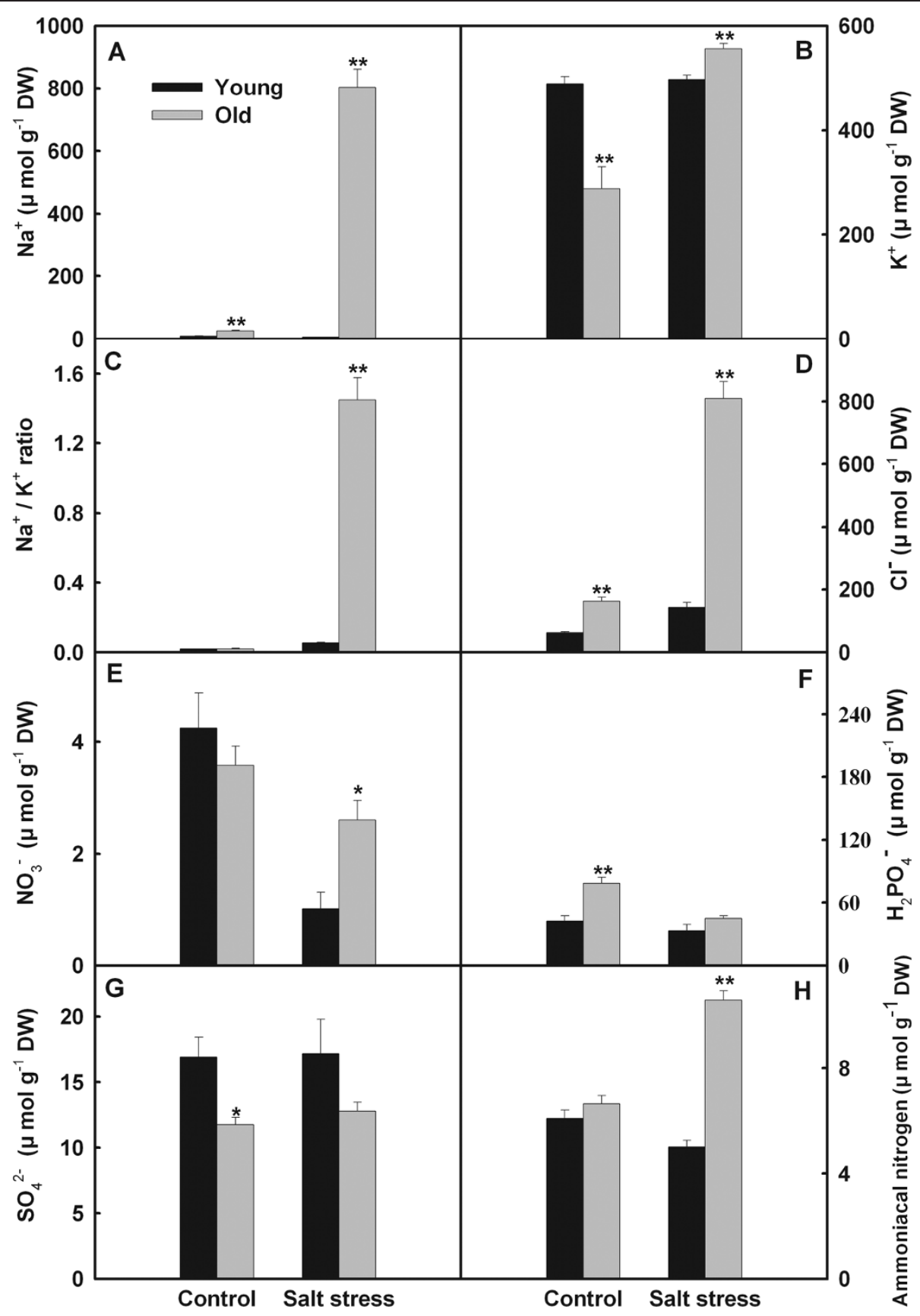

Figure 1 Effects of salt stress on the contents of inorganic ions in young and old leaves of rice seedlings. The values are means ( \pm SE) of four biological replicates, and each replicate consisted of a pool of 10 plants. Statistically significant between organs at same stress condition was determined by $t$-test, and marked as $*(P<0.05)$ and ${ }^{* *}(P<0.01)$.

OsNRT2;1 in old leaves and up-regulated the expression of OsNRT2;1 in young leaves (Figure 6). Expression level of OsAMT1;1 was much higher than other AMT gene family members (Table 1). Responses of OsAMT family members to salt stress were diverse. For example, salt stress strongly enhanced the expression of OsAMT1;1 in young leaves but up-regulated the expression of OsAMT2;1 in old leaves (Figure 6). In addition, salt stress strongly reduced the expression of OsAMT1;2, OsAMT2;3, OsAMT3;1 and OsAMT3;3 in old leaves.

\section{Discussion}

lon balance

Salt stress has a more complex effect on the ion balance in rice old leaves than in young leaves. The results indicated that salt stress only slightly influenced the 


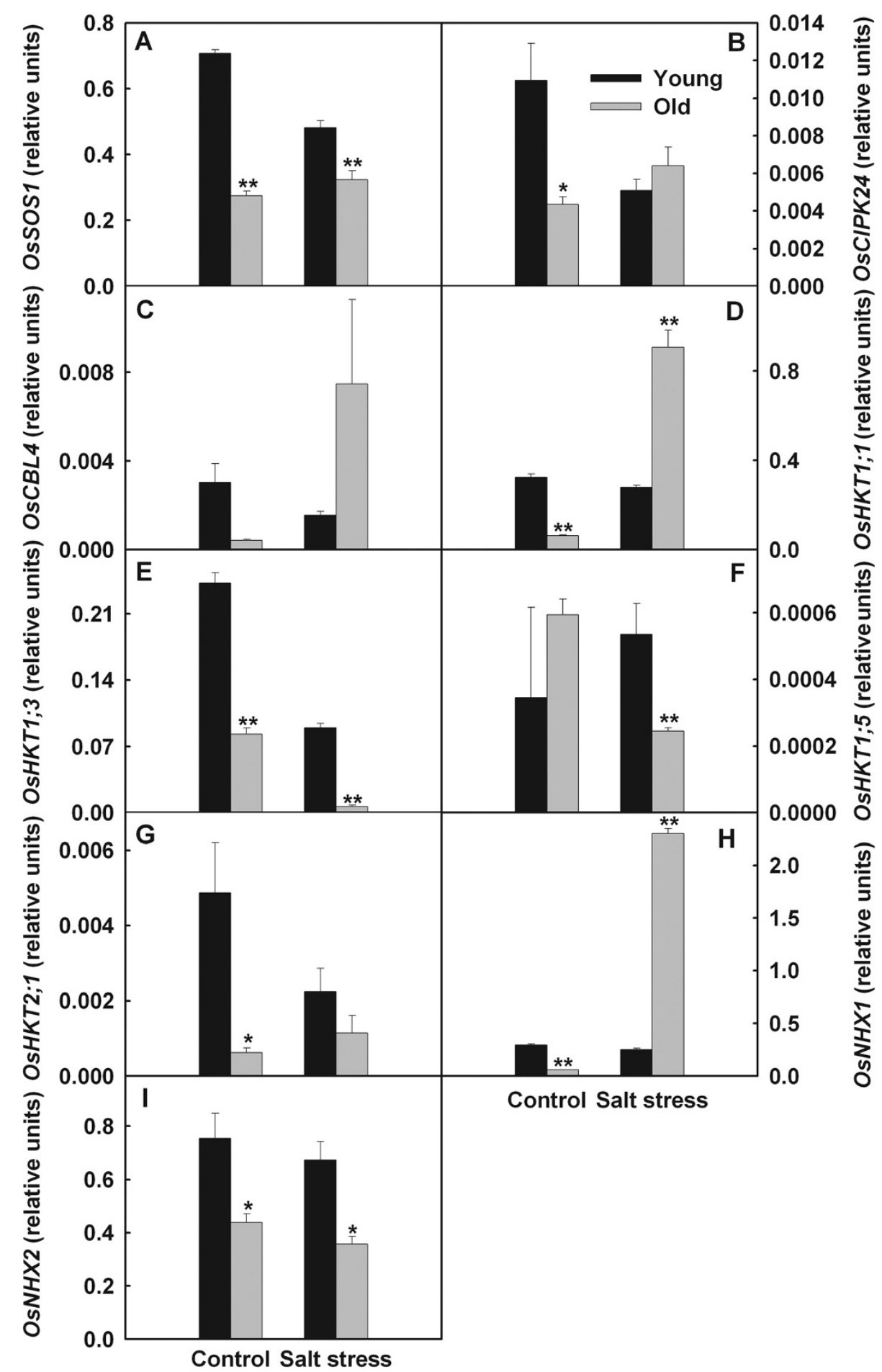

Figure 2 Effects of salt stress on the expression of OsSOS pathway genes and OsHKT gene family in young and old leaves of rice seedlings. The values are means ( \pm SE) of four biological replicates, and each replicate consisted of a pool of 10 plants. Statistically significant between organs at same stress condition was determined by $t$-test, and marked as $*(P<0.05)$ and ${ }^{* *}(P<0.01)$.

accumulations of $\mathrm{Na}^{+}, \mathrm{K}^{+}, \mathrm{Cl}^{-}$and ammoniacal nitrogen in young leaves, but salt stress strongly stimulated their accumulation in old leaves (Figure 1). Interestingly, salt stress did not limit accumulations of $\mathrm{SO}_{4}^{2-}$ and $\mathrm{H}_{2} \mathrm{PO}_{4}^{-}$in rice leaves. It might be main reason for this that salt stress did not influence uptake of $\mathrm{SO}_{4}^{2-}$ and $\mathrm{H}_{2} \mathrm{PO}_{4}^{-}$. Rice plants protected young leaves from ion injury via mightily accumulating toxicant ions in old leaves. Mature leaves have a 


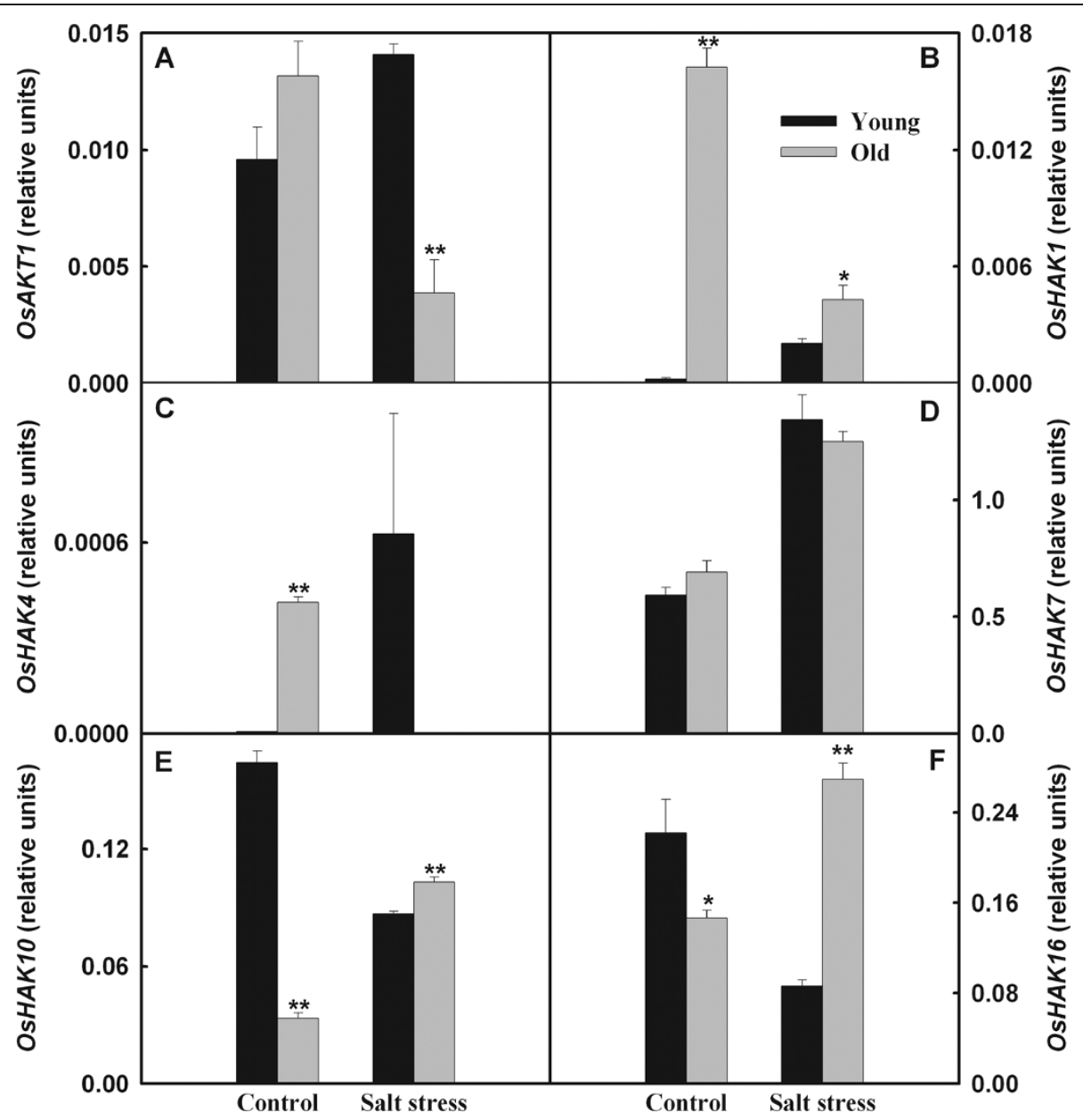

Figure 3 Effects of salt stress on the expression of OsAKT1 and OsHAK gene family in young and old leaves of rice seedlings. The values are means ( \pm SE) of four biological replicates, and each replicate consisted of a pool of 10 plants. Statistically significant between organs at same stress condition was determined by $t$-test, and marked as * $(P<0.05)$ and $* *(P<0.01)$.

larger vacuole while young leaf cells only have dispersed miniature vacuoles [13]. Rice plants may transport toxicant ions (e.g. $\mathrm{Na}^{+}$and $\mathrm{Cl}^{-}$) into the vacuoles of old leaves to alleviate the ion toxicity of whole plant.

Under salt stress, $\mathrm{Na}^{+}$competes with $\mathrm{K}^{+}$for uptake into roots [14]. When $\mathrm{Na}^{+}$enters cells and accumulates to high levels, it becomes toxic to enzymes. Tolerance of plants to $\mathrm{Na}^{+}$stress relies on $\mathrm{Na}^{+}$compartmentation at the cellular and tissue levels, $\mathrm{Na}^{+}$exclusion and the control of longdistance transport in vasculatures [13]. Salt overly sensitive (SOS) salt tolerance pathway may play important roles in $\mathrm{Na}^{+}$release from leaves to roots. It has been reported that rice OsHKT1;5 mediates $\mathrm{Na}^{+}$release from shoots to roots $[3,8]$. In higher plants, the $\mathrm{Na}^{+} / \mathrm{H}^{+}$exchanger (NHX) family mediates $\mathrm{Na}^{+}$compartmentalization into vacuoles [6]. Under salt stress, up-regulated $O s N H X 1$ expression might contribute to $\mathrm{Na}^{+}$compartmentalization in old leaves. Up-regulation of OsHKT1;1, OsHAK10 and OsHAK16 may advance the accumulation of $\mathrm{Na}^{+}$in old leaves of salt stressed-rice (Figure 7). In addition, lower expression of OsHKT1;5 and OsSOS1 in old leaves may decrease frequency of retrieving $\mathrm{Na}^{+}$from old leaf cells (Figure 7).

\section{Nitrogen metabolism}

Nitrogen metabolism regulation is of central importance for salt tolerance, and interference between salinity and nitrogen nutrition is a very complex network affecting almost all processes [5]. Our results indicated that salt stress has a stronger effect on nitrogen metabolism in old leaves than in young leaves. Under salt stress, old leaves showed higher concentration of $\mathrm{NO}_{3}^{-}$content than young leaves. Under salt stress, these scarce $\mathrm{NO}_{3}^{-}$may be principally stored in old leaves with larger vacuole to keep the $\mathrm{NO}_{3}^{-}$supply in shoots [13]. The up-regulation of OsNRT1;2, a gene coding nitrate transporter, might advance the accumulation of $\mathrm{NO}_{3}^{-}$in the old leaves of salt stressed-rice. Our results also showed that salt stress has different effects on OsAMT gene family expression of young and old leaves (Figure 6). This indicated that 

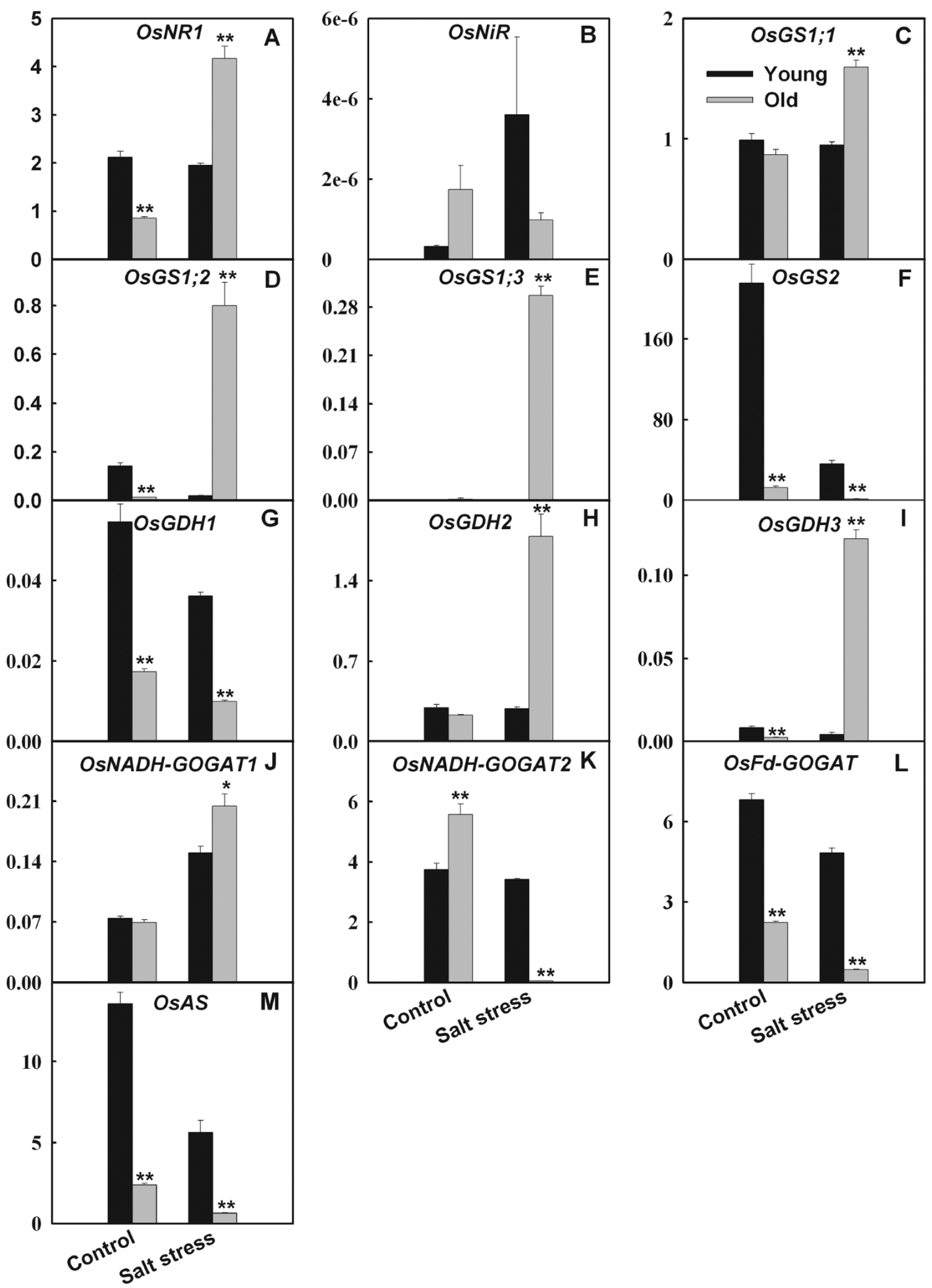

Figure 4 Effects of salt stress on the expression (relative units) of genes involved in $\mathrm{NH}_{4}^{+}$assimilation in young and old leaves of rice seedlings. The values are means ( \pm SE) of four biological replicates, and each replicate consisted of a pool of 10 plants. Statistically significant between organs at same stress condition was determined by $t$-test, and marked as $*(P<0.05)$ and ${ }^{* *}(P<0.01)$. 


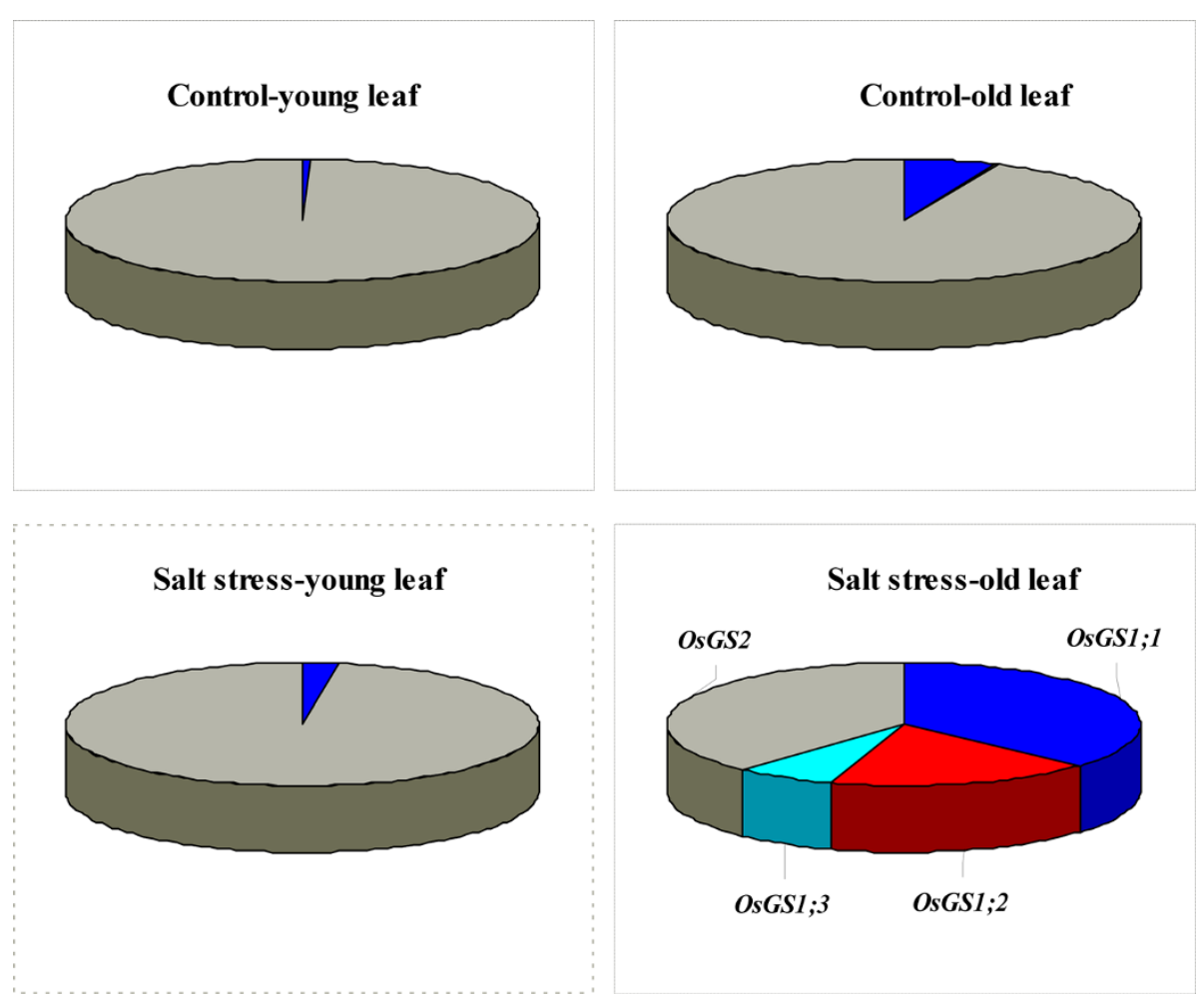

Figure 5 Percent contribution of different OsGS gene family members to total OsGS expression in young and old leaves of rice seedlings under salt stress.

young and old leaves might have different $\mathrm{NH}_{4}^{+}$transmission mechanisms under salt stress.

It is well known that $\mathrm{NO}_{3}^{-}$is reduced to nitrite by nitrate reductase (NR) and then to $\mathrm{NH}_{4}^{+}$by nitrite reductase (NiR). $\mathrm{NH}_{4}^{+}$is incorporated into amino acid by glutamine synthetase (GS) and glutamate synthase (FdGOGAT and NADH-GOGAT) or alternative glutamate dehydrogenase $(\mathrm{GDH})$ pathway (reviewed by Shi et al. 2010) [15]. Glutamine synthetase (GS) includes two isozymes: GS1 in the cytosol and GS2 in chloroplasts/ plastids [16]. OsNADH-GOGAT is mainly expressed in roots and mediates assimilation of $\mathrm{NH}_{4}^{+}$in roots, and Fd-GOGAT exists in chloroplast and functions in assimilation of $\mathrm{NH}_{4}^{+}$from photorespiration [13]. Our results indicated that the expression levels of OsFdGOGAT and OsGS2 in old leaves were much lower than those in young leaves in response of rice plants to salt stress. The down-regulation of OsGS2 and OsFd-GOGAT in old leaves might be a harmful response to excesses of $\mathrm{Na}^{+}$and $\mathrm{Cl}^{-}$. Under salt stress, rice might accumulate $\mathrm{Na}^{+}$ and $\mathrm{Cl}^{-}$to toxic levels in old leaves (Figure 1A). This might harm the chloroplast, influence photorespiration process, and reduce $\mathrm{NH}_{4}^{+}$production from photorespiration, which immediately down-regulates the OsGS2 and OsFdGOGAT in old leaves of salt stressed rice (Figure 7). Excesses of $\mathrm{Na}^{+}$and $\mathrm{Cl}^{-}$even changed the pathway of $\mathrm{NH}_{4}^{+}$ assimilation in old leaves, weakened GOGAT/GS pathway and elevated GDH pathway (Figure 7). We found that salt stress clearly elevated the expression levels of $\mathrm{OsGDH2}$ and $O s G D H 3$ in old leaves, while strongly down-regulated the expression of OsGS2 and OsFd-GOGAT in old leaves (Figure 4). In addition, salt stress could change spatial distribution of various members of same gene family at whole plant level. For example, OsGS1;3 is present only in the spikelets [16], but salt stress strongly stimulated its expression in old leaves (Figure 4E). Under control condition, expression level of OsGS2 was much higher than other OsGS family members (Figure 5). Under salt stress, percent contribution of OsGS2 to total OsGS expression in young leaves still was much higher than other members; however, in old leaves, expression of all OsGS1 gene family members were clearly up-regulated and resulted in the reduction of percent contribution of OsGS2 (Figures 5 and 6).

\section{Conclusions}

Salt stress has a more complex effect on the ion balance in rice old leaves than in young leaves. Rice plants protect young leaves from ion injury via mightily accumulating toxicant ions in old leaves. Mature leaves have a larger vacuole while young leaf cells only have dispersed miniature vacuoles. Rice plants may transport toxicant ions (e.g. $\mathrm{Na}^{+}$and $\mathrm{Cl}^{-}$) into the vacuoles of old leaves to 

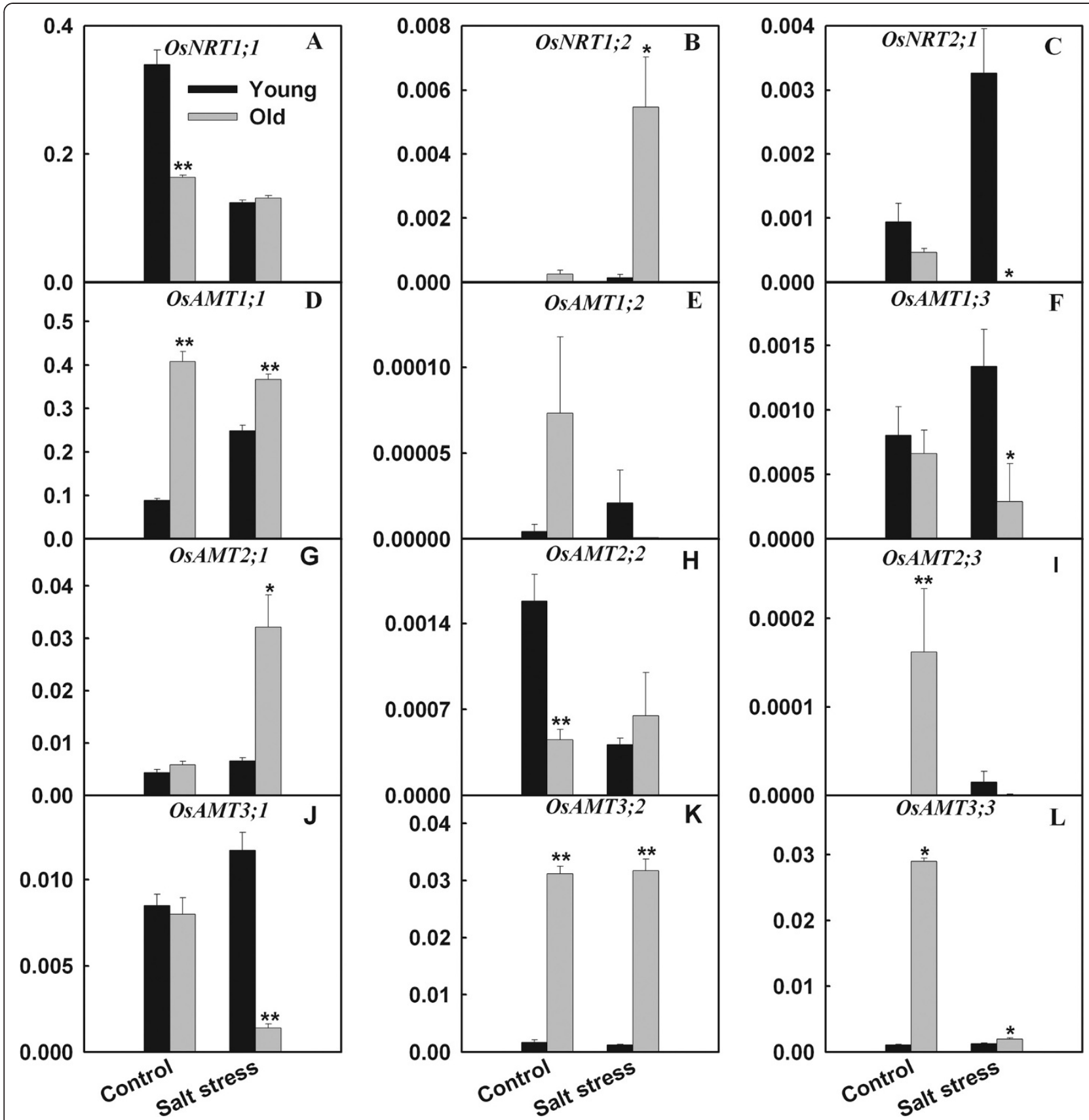

Figure 6 Effects of salt stress on the expression (relative units) of OsAMT and OsNRT gene families in young and old leaves of rice seedlings. The values are means ( \pm SE) of four biological replicates, and each replicate consisted of a pool of 10 plants. Statistically significant between organs at same stress condition was determined by $t$-test, and marked as $*(P<0.05)$ and ${ }^{* *}(P<0.01)$.

alleviate the ion toxicity of whole plant. Under salt stress, up-regulation of OsHKT1;1, OsHAK10 and OsHAK16 advances the accumulation of $\mathrm{Na}^{+}$in old leaves. In addition, lower expression of OsHKT1;5 and OsSOS1 in old leaves decreases frequency of retrieving $\mathrm{Na}^{+}$from old leaf cells. Excess of $\mathrm{Na}^{+}$weakens GOGAT/GS pathway and elevates GDH pathway in old leaves. The upregulation of OsNRT1;2 advances the accumulation of $\mathrm{NO}_{3}^{-}$in the old leaves of salt stressed-rice.

\section{Methods}

Plant growth conditions

Matsumae, a major rice cultivar in north China, was chosen as the test organism. Matsumae as salt tolerance rice cultivar can grow in the moderate-salinized field of northeast China. Seeds were germinated and grown in petri dishes for $6 \mathrm{~d}$ in a growth cabinet $\left(29^{\circ} \mathrm{C}\right.$ during the day and $25^{\circ} \mathrm{C}$ during the night, $16 / 8 \mathrm{~h}$ photoperiod at $250 \mu \mathrm{mol} \mathrm{m} \mathrm{m}^{-2} \mathrm{~s}^{-1}$ ). Seedlings were then transferred to 
Table 1 Percent contribution of different OsAMT gene family members to total OsAMT expression in young and old leaves of rice seddlings under salt stress

\begin{tabular}{llllll}
\hline & \multicolumn{2}{c}{ Young leaf } & & \multicolumn{2}{c}{ Old leaf } \\
\cline { 2 - 3 } & Control & Salt stress & & Control & Salt stress \\
\hline OsAMT1;1(\%) & 83.142 & 91.732 & & 84.405 & 84.36 \\
\hline OsAMT1;2 (\%) & 0.004 & 0.008 & 0.015 & 0.0002 \\
\hline OsAMT1;3 (\%) & 0.757 & 0.494 & 0.137 & 0.067 \\
\hline OsAMT2;1 (\%) & 4.059 & 2.413 & 1.198 & 7.3793 \\
\hline OsAMT2;2 (\%) & 1.490 & 0.152 & 0.094 & 0.1488 \\
\hline OsAMT2;3 (\%) & 0.001 & 0.006 & 0.034 & 0.0003 \\
\hline OsAMT3;1 (\%) & 8.000 & 4.313 & 1.656 & 0.3169 \\
\hline OsAMT3;2 (\%) & 1.567 & 0.434 & 6.463 & 7.2836 \\
\hline OsAMT3;3 (\%) & 0.979 & 0.449 & 5.998 & 0.4434 \\
\hline
\end{tabular}

buckets containing $2000 \mathrm{~mL}$ of sterile nutrient solution for solution culture. The nutrient solution was replaced daily. The buckets were placed in a growth chamber that was maintained at $27.0 \pm 1.5^{\circ} \mathrm{C}$ during the day and $22.0 \pm 1.5^{\circ} \mathrm{C}$ during the night, under a $16 / 8 \mathrm{~h}$ photoperiod at $250 \mu \mathrm{mol} \mathrm{m} \mathrm{m}^{-2} \mathrm{~s}^{-1}$. The nutrient solution used in this work accorded to the components described by the International Rice Research Institute [17], and contained $1.44 \mathrm{mM} \mathrm{NH}_{4} \mathrm{NO}_{3}, 0.32 \mathrm{mM} \mathrm{NaH} \mathrm{PO}_{4}, 0.6 \mathrm{mM}$
$\mathrm{K}_{2} \mathrm{SO}_{4}, 1.0 \mathrm{mM} \mathrm{CaCl}, 1.6 \mathrm{mM} \mathrm{MgSO}_{4}, 0.072 \mathrm{mM} \mathrm{Fe}-$ EDTA, $0.2 \mu \mathrm{mM} \mathrm{Na} \mathrm{SiO}_{3}, 9.1 \mu \mathrm{M} \mathrm{MnCl}_{2}, 0.154 \mu \mathrm{M}$ $\mathrm{ZnSO}_{4}, 0.156 \mu \mathrm{M} \mathrm{CuSO}_{4}, 18.5 \mu \mathrm{M} \mathrm{H}_{3} \mathrm{BO}_{3}$ and $0.526 \mu \mathrm{M}$ $\mathrm{H}_{2} \mathrm{MoO}_{4}$ at $\mathrm{pH}$ 5.2.

\section{Stress treatment}

After 22 days of growth in hydroponic medium, rice plants were subjected to salt stress $(100 \mathrm{mM} \mathrm{NaCl})$ by transferring them to another barrel containing $2000 \mathrm{~mL}$ of the treatment solution amended with the above nutrients and $100 \mathrm{mM} \mathrm{NaCl}$. A bucket including 20 seedlings represented one replicate, and there were four replicates per treatment. 8 buckets of seedlings were randomly divided into 2 sets, four buckets per set. Each bucket was considered as one replicate with four replicates per set, one set was used as control, and another set was treated with salt stress. Treatment solutions were replaced daily. The nutrient solution without stress salts was used as control. The 20 seedlings in each bucket were harvested after treatment for $6 \mathrm{~d}$.

\section{Measurements of physiological indices}

Old leaf was defined as second leaf at bottom, and young leaf as newly emerged leaf. The young and old leaves of 10 seedlings in each bucket were separated and mixed, then immediately frozen in liquid nitrogen and then

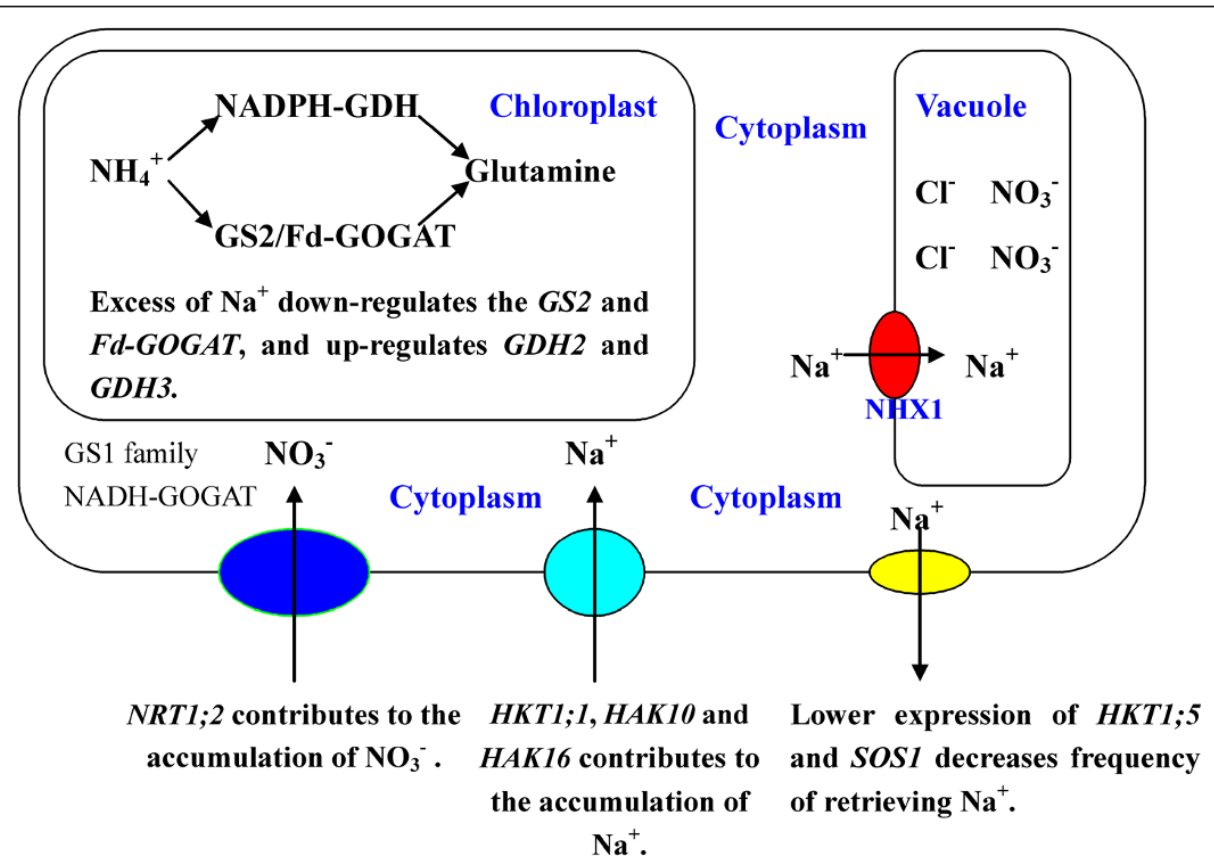

Figure 7 lon balance and nitrogen metabolism responses of old leaves of rice seedlings under salt stress. Under salt stress, old leaves accumulates much higher concentrations of $\mathrm{Na}^{+}, \mathrm{Cl}^{-}$and $\mathrm{NO}_{3}^{-}$than young leaves. Under salt stress, up-regulation of OsHKT1;1, OsHAK10 and OsHAK16 advances the accumulation of $\mathrm{Na}^{+}$in old leaves, and increased OsNHX1 expression contributes to $\mathrm{Na}^{+}$compartmentalization in old leaves. In addition, lower expression of OsHKT1;5 and OsSOS1 in old leaves decreases frequency of retrieving $\mathrm{Na}^{+}$from old leaf cells. Excess of $\mathrm{Na}^{+}$ weakens GOGAT/GS pathway and elevates GDH pathway in old leaves. The up-regulation of OsNRT1;2, a gene coding nitrate transporter, advances the accumulation of $\mathrm{NO}_{3}^{-}$in the old leaves of salt stressed-rice. 
stored at $-70^{\circ} \mathrm{C}$ for RNA isolation. Another 10 seedlings in each bucket were washed with distilled water, after which the old and young leaves were separated and freeze-dried. Dry samples of plant material were treated with $10 \mathrm{~mL}$ deionized water at $100^{\circ} \mathrm{C}$ for $1 \mathrm{~h}$, and the extract used to determine the contents of free inorganic ions. The contents of $\mathrm{NO}_{3}^{-}, \mathrm{Cl}^{-}, \mathrm{H}_{2} \mathrm{PO}_{4}^{-}$, and $\mathrm{SO}_{4}^{2-}$ were determined by ion chromatography (DX-300 ion chromatographic system; AS4A-SC ion-exchange column, CD M-II electrical conductivity detector, mobile phase: $\mathrm{Na}_{2} \mathrm{CO}_{3} / \mathrm{NaHCO}_{3}=1.7 / 1.8 \mathrm{mM}$; DIONEX, Sunnyvale, USA). Ammoniacal nitrogen was measured by ninhydrin colourimetry methods [18]. A flame photometer was used to determine $\mathrm{K}^{+}$and $\mathrm{Na}^{+}$contents.

\section{Quantitative real time PCR analysis}

We extracted the total RNA from the young and old leaves of seedlings grown under stress or non-stress conditions using TRIzol reagent (Invitrogen). The RNA was treated with DNaseI (Invitrogen), reverse-transcribed using SuperScriptTM RNase H-Reverse Transcriptase (Invitrogen), and then subjected to real-time PCR analysis using gene-specific primers. The gene-specific primers and corresponding references are listed in Additional file 1. PCR amplification was conducted with an initial step at $95^{\circ} \mathrm{C}$ for $1 \mathrm{~min}$ followed by 45 cycles of $5 \mathrm{~s}$ at $95^{\circ} \mathrm{C}, 10 \mathrm{~s}$ at $60^{\circ} \mathrm{C}$ and $30 \mathrm{~s}$ at $72^{\circ} \mathrm{C}$. Amplification of the target gene was monitored every cycle by SYBR Green. Amplification of the rice $U B Q 5$ (GenBank Accession AK061988) mRNA was used as an internal quantitative control [19-21]. The relative expression of the target genes was calculated using the $\triangle \mathrm{Ct}$ method [22]. We optimized PCR reaction system, after which the amplification efficiencies of each target gene and reference gene were approximately equal.

\section{Statistical analysis}

Statistical analysis of the data was performed using the statistical program SPSS 13.0 (SPSS, Chicago, USA). All data were represented by an average of the four biological replicates and the standard errors (S.E.). Statistically significant between old and young leaves at same stress condition was determined by $t$ test.

\section{Additional file}

Additional file 1: Table S1. Gene-specific primers used in real time PCR analysis.

\section{Abbreviations}

NR: Nitrate reductase; NiR: Nitrite reductase; GOGAT: Glutamate synthase; GS: Glutamine synthetase; GDH: Glutamate dehydrogenase; AS: Asparagine synthetase; NRT: Nitrate transporter; AMT: Ammonium transporter; NHX: $\mathrm{Na}^{+} / \mathrm{H}^{+}$exchanger; HKT: High affinity $\mathrm{K}^{+}$transporter; HAK: KUP/HAK/KT K $\mathrm{K}^{+}$ transporter; AKT: Low affinity $\mathrm{K}^{+}$transporter; SOS: Salt overly sensitive; CBL: Calcineurin B-like protein; CIPK: CBL-interacting protein kinase.

\section{Competing interests}

The authors have declared that no competing interests exist.

\section{Authors' contributions}

$\mathrm{CY}$ and $\mathrm{HW}$ designed the study. $\mathrm{CY}, \mathrm{HW}$, and RG performed the experiments. $\mathrm{CY}, \mathrm{HW}, \mathrm{XL}, \mathrm{BL}$ and DS analysed the data. $\mathrm{CY}$ and HW wrote the manuscript, which was further edited by BL and DS. All authors read and approved the final manuscript.

\section{Acknowledgments}

This study was supported by the State Key Basic Research and Development Plan of China (2011CB100205), the Programme for Introducing Talents to Universities (No. B07017), the National Natural Science Foundation of China Project (Nos. 31072078 and 30970232), Project of the Jilin Provincial Government (No. 20106023), Basic Research Project by Jilin Provincial Government (No. 20090567), the Ministry of Agriculture "948" project (No. 2006-G51), and the Fundamental Research Funds for the Central Universities (Nos. 11QNJJ020 and 10SSXT143). We thank the two anonymous reviewers for the critical and constructive comments for further improving of the manuscript.

\section{Author details}

${ }^{1}$ Key laboratory of Molecular Epigenetics of MOE, Northeast Normal University, Changchun 130024 Jilin Province, China. ${ }^{2}$ Department of Agronomy, Jilin Agricultural University, Changchun 130118 Jilin Province, China. ${ }^{3}$ Institute of Environment and Sustainable Development in Agriculture (IEDA), Chinese Academy of Agricultural Sciences (CAAS), Key Laboratory of Dry land Agriculture, MOA, Beijing 100081, China. ${ }^{4}$ Rice Institute, Jilin Academy of Agricultural Sciences, Changchun 130033 Jilin Province, China.

Received: 2 August 2012 Accepted: 17 October 2012

Published: 21 October 2012

\section{References}

1. Ashraf $M$, Harris P: Potential biochemical indicators of salinity tolerance in plants. Plant Sci 2004, 166(1):3-16.

2. Munns R: Comparative physiology of salt and water stress. Plant Cell Environ 2002, 25(2):239-250.

3. Parida AK, Das AB: Salt tolerance and salinity effects on plants: a review. Ecotox Environ Safe 2005, 60:324-349.

4. Niu X, Bressan RA, Hasegawa PM, Pardo JM: Ion homeostasis in $\mathrm{NaCl}$ stress environments. Plant Physiology 1995, 109(3):735.

5. Läuchli A, Lüttge U: Salinity: Environment-plants-molecules. Boston: Boston Kluwer Academic Publishers; 2002.

6. Munns R, Tester M: Mechanisms of salinity tolerance. Annu Rev Plant Biol 2008, 59:651-681.

7. Yasar F, Uzal O, Tufenkci S, Yildiz K: Ion accumulation in different organs of green bean genotypes grown under salt stress. Plant Soil Environ 2006, 52(10):476-480.

8. Vera-Estrella R, Barkla BJ, Garcia-Ramirez L, Pantoja O: Salt stress in Thellungiella halophila activates $\mathrm{Na}^{+}$transport mechanisms required for salinity tolerance. Plant Physiol 2005, 139(3):1507-1517.

9. Nakamura T, Ishitani M, Harinasut P, Nomura M, Takabe T: Distribution of glycinebetaine in old and young leaf blades of salt-stressed barley plants. Plant Cell Physiol 1996, 37(6):873-877.

10. Hajlaoui H, Ayeb NE, Garrec JP, Denden M: Differential effects of salt stress on osmotic adjustment and solutes allocation on the basis of root and leaf tissue senescence of two silage maize (Zea mays L.) varieties. Ind Crop Prod 2010, 31(1):122-130.

11. Ashraf M, O'Leary JW: Ion distribution in leaves of salt-tolerant and salt-sensitive lines of spring wheat under salt stress. Acta Bot Neer 1997, 46(2):207-218.

12. Akram MS, Ali Q, Athar HUR, Bhatti AS: Ion uptake and distribution in Panicum antidotale Retz. under salt stress. Pak J Bot 2006, 38(5):1661-1669.

13. Wang H, Wu Z, Han J, Zheng W, Yang C: Comparison of Ion Balance and Nitrogen Metabolism in Old and Young Leaves of Alkali-Stressed Rice Plants. PloS One 2012, 7(5):e37817. 
14. Zhu JK: Regulation of ion homeostasis under salt stress. Curr Opin Plant Biol 2003, 6(5):441-445.

15. Shi WM, Xu WF, Li SM, Zhao XQ, Dong GQ: Responses of two rice cultivars differing in seedling-stage nitrogen use efficiency to growth under lownitrogen conditions. Plant Soil 2010, 326(1):291-302.

16. Kusano M, Tabuchi M, Fukushima A, Funayama K, Diaz C, Kobayashi M, Hayashi N, Tsuchiya YN, Takahashi H, Kamata A: Metabolomics data reveal a crucial role of cytosolic glutamine synthetase $1 ; 1$ in coordinating metabolic balance in rice. Plant J 2011, 66:456-466.

17. Yoshida S, Forno DA, Cock JH, Gomez KA: Laboratory manual for physiological studies of rice. Los Banos: International rice research institute; 1976.

18. Zhang Z: Laboratory Manual of Plant Physiology. 234th edition. Beijing: Higher education press; 2004

19. Zang A, Xu X, Neill S, Cai W: Overexpression of OsRAN2 in rice and Arabidopsis renders transgenic plants hypersensitive to salinity and osmotic stress. J Exp Bot 2010, 61(3):777-789.

20. Muriel Q, Alexis N, Isabelle L, Be'atrice L, Christine C, Dupont G, Stanley L: Putrescine differently influences the effect of salt stress on polyamine metabolism and ethylene synthesis in rice cultivars differing in salt resistance. J Exp Bot 2010, 61:2719-2733.

21. Jain M, Nijhawan A, Tyagi AK, Khurana JP: Validation of housekeeping genes as internal control for studying gene expression in rice by quantitative real-time PCR. Biochem Biop Res Co 2006, 345(2):646-651.

22. Livak KJ, Schmittgen TD: Analysis of relative gene expression data using real-time quantitative PCR and the 2(-Delta Delta C(T)) Method. Methods 2001, 25(4):402-408.

doi:10.1186/1471-2229-12-194

Cite this article as: Wang et al:: Effects of salt stress on ion balance and nitrogen metabolism of old and young leaves in rice (Oryza sativa L.). BMC Plant Biology 2012 12:194.

\section{Submit your next manuscript to BioMed Central and take full advantage of:}

- Convenient online submission

- Thorough peer review

- No space constraints or color figure charges

- Immediate publication on acceptance

- Inclusion in PubMed, CAS, Scopus and Google Scholar

- Research which is freely available for redistribution 